\title{
Laparoscopic Resection of Large Adrenal Tumors
}

\author{
George N. Zografos, MD, Athanasios Farfaras, George Vasiliadis, MD, Theodora Pappa, MD, \\ Chrysanthi Aggeli, MD, Evagelina Vasilatou, MD, Gregory Kaltsas, MD, PhD, George Piaditis, MD
}

\begin{abstract}
Background: Laparoscopic adrenalectomy has rapidly replaced open adrenalectomy as the procedure of choice for benign adrenal tumors. It still remains to be clarified whether the laparoscopic resection of large $(\geq 8 \mathrm{~cm})$ or potentially malignant tumors is appropriate or not due to technical difficulties and concern about local recurrence. The aim of this study was to evaluate the short- and long-term outcome of 174 consecutive laparoscopic and open adrenalectomies performed in our surgical unit.
\end{abstract}

Methods: Our data come from a retrospective analysis of 174 consecutive adrenalectomies performed on $166 \mathrm{pa}-$ tients from May 1997 to December 2008. Fifteen patients with tumors $\geq 8 \mathrm{~cm}$ underwent laparoscopic adrenalectomy. Sixty-five patients were men and 101 were women, aged 16 years to 80 years. Nine patients underwent either synchronous or metachronous bilateral adrenalectomy. Tumor size ranged from $3.2 \mathrm{~cm}$ to $27 \mathrm{~cm}$. The largest laparoscopically excised tumors were a ganglioneuroma with a mean diameter of $13 \mathrm{~cm}$ and a myelolipoma of $14 \mathrm{~cm}$.

Results: In 135 patients, a laparoscopic procedure was completed successfully, whereas in 14 patients the laparoscopic procedure was converted to open. Seventeen patients were treated with an open approach from the start. There were no conversions in the group of patients with tumors $>8 \mathrm{~cm}$. Operative time for laparoscopic adrenalectomies ranged from 65 minutes to 240 minutes. In the large adrenal tumor group, operative time for laparoscopic resection ranged from 150 minutes to 240 minutes. The postoperative hospital stay for laparo-

Third Department of Surgery, Athens General Hospital «G. Gennimatas Greece (Drs Zografos, Farfaras, Vasiliadis, Aggeli).; Department of Endocrinology, Athens General Hospital «G. Gennimatas $\gg$, Greece (Drs Pappa, Vasilatou, Kaltsas, Piaditis).

\section{Scientific Paper}

Paper selected as oral presentation at the $17^{\text {th }}$ EAES Congress, Prague, June 17-20, 2009 .

Address correspondence to: G.N. Zografos, MD, 10 Oyrani Street, Athens, 15237, Greece. Telephone: +306944918944, Fax: +302107706915, E-mail: gnzografos@ yahoo.com

DOI: $10.4293 / 108680810 X 12924466007160$

(C) 2010 by JSLS, Journal of the Society of Laparoendoscopic Surgeons. Published by the Society of Laparoendoscopic Surgeons, Inc. scopic adrenalectomy ranged from 1 day to 2 days (mean, 1.5) and from 5 days to 20 days for patients undergoing the open or converted procedure. The mean postoperative stay was 2 days for the group with large tumors resected by laparoscopy.

Conclusion: Laparoscopic resection of large $(\geq 8 \mathrm{~cm})$ adrenal tumors is feasible and safe. Short- and long-term results did not differ in the 2 groups.

Key Words: Large adrenal tumors, Laparoscopic adrenalectomy, Adrenalectomy.

\section{INTRODUCTION}

The first laparoscopic adrenalectomy was performed by Michel Gagner in 1992. ${ }^{1}$ Since then, it has become the standard surgical approach for all benign adrenal tumors. Compared with traditional open resection, laparoscopic adrenalectomy is associated with less postoperative pain, shorter hospital stay and recovery time, and better patient satisfaction rates. These clear advantages of laparoscopic adrenalectomy did not encourage any prospective randomized controlled trials comparing the new technique with the classical "open," either transabdominal or retroperitoneal technique. However, the laparoscopic approach has not been widely accepted as appropriate for the resection of larger adrenal tumors. ${ }^{2}$ A tumor size of $6 \mathrm{~cm}$ and later $8 \mathrm{~cm}$ has been considered as the upper limit for laparoscopic adrenalectomy. ${ }^{3}$ The risk of malignancy as well as technical difficulties were the main concerns in applying the laparoscopic approach in large adrenal tumors. ${ }^{4}$ In this article, we highlight the technical aspects and results of laparoscopic surgery for adrenal tumors $>8 \mathrm{~cm}$ to determine the feasibility and safety of the procedure.

\section{MATERIALS AND METHODS}

From May 1997 to December 2008, 166 patients with adrenal tumors were hospitalized in our Department, and 174 adrenalectomies were performed. Sixty-five patients were men and 101 women, aged from 16 to 80. Nine patients underwent either synchronous or metachronous 
bilateral adrenalectomy. Four of these subjects had Cushing's disease, one had bilateral micronodular pigmental hyperplasia, one patient had MEN IIA syndrome, one metachronous solitary metastasis from colorectal cancer, one bilateral adenoma, and one adrenocortical carcinoma with contralateral large adenoma. The most common adrenal masses were adenomas, pheochromocytomas, Cushing's syndrome, aldosteronomas, and malignant tumors (Table 1).

In 15 patients, adrenal tumor size, as measured on the uncut specimen in the Pathology Department, was $\geq 8 \mathrm{~cm}$ (Table 2). All patients underwent laparoscopic adrenalectomy if their computerized tomography (CT) or magnetic resonance imaging (MRI) showed no invasion of periadrenal tissues or organs, and the adrenal tumor was $<12 \mathrm{~cm}$ to $13 \mathrm{~cm}$. Endocrinological evaluation and complete adrenal dynamic testing were performed to determine whether the tumor was functional. In all patients with pheochromocytoma alpha-adrenergic blockade was administered at least 10 days prior to surgery.

\section{Technical Aspects of Laparoscopic Adrenalectomy}

We prefer the transperitoneal lateral decubitus approach, as the best for maximal exposure of the gland and adjacent organs and vessels. On the right side, we use three

Table 1.

Indications for Adrenalectomy

\begin{tabular}{ll}
\hline Diagnosis & $\begin{array}{l}\text { Number of } \\
\text { Cases }\end{array}$ \\
\hline $\begin{array}{l}\text { Adenomas (25 functioning subclinical } \\
\text { tumors) }\end{array}$ & 58 \\
$\begin{array}{l}\text { Cushing's syndrome (22 adenomas) } \\
\text { Cushing's disease }\end{array}$ & 25 \\
Pheochromocytomas (4 extra adrenal, & 5 \\
1MEN IIa) & 32 \\
Malignant pheochromocytoma & \\
Recurrence of malignant & 1 \\
pheochromocytoma & 1 \\
Solitary metastases (lung, colorectal, \\
renal) \\
Adrenocortical adenocarcinomas \\
Conn' s syndrome (22 adenomas) \\
Myelolipomas \\
Cysts \\
Ganglioneuromas \\
Hematomas
\end{tabular}

10-mm trocars and one 5-mm trocar. On the left side, we use two 10-mm trocars and two 5-mm trocars. We prefer to create pneumoperitoneum with the Hasson technique to avoid any relevant morbidity.

\section{Right Adrenalectomy}

The right triangular ligament and the retroperitoneal liver attachments are cauterized and divided to allow liver retraction and expose the upper limits of the tumor. Liver mobilization is necessary especially in large tumors. After dividing the retroperitoneum, the inferior vena cava (IVC) is identified and dissected from the tumor. The periadrenal fat is gently pushed upwards with endo-peanuts. The adrenal vein is subsequently identified, dissected, double-clipped, and divided. The inferior and superior adrenal vessels are cauterized or clipped. Ultrasonic scissors are occasionally used after ligation of the adrenal vein.

\section{Left Adrenalectomy}

The left colonic flexure is always mobilized in large tumors and the left upper renal pole exposed. The splenic attachments are cauterized and divided, and the tail of the pancreas identified. The spleen is further mobilized until the stomach is visualized. Gerota's fascia is then opened, the adrenal gland identified, and the adrenal vein dissected, double clipped, and divided. The renal vein is

Table 2.

Tumors $>8 \mathrm{~cm}$ Resected Laparoscopically

\begin{tabular}{ll}
\hline Diagnosis & Tumor Size $(\mathrm{cm})$ \\
\hline Myelolipoma & $14 \times 10$ \\
Ganglioneuroma & $13 \times 9.5$ \\
Pheochromocytoma & $11 \times 6.5$ \\
Adrenocortical adenocarcinoma & $10.5 \times 7.5$ \\
Pheochromocytoma & $10.5 \times 7$ \\
Adenoma & $10 \times 6$ \\
Cyst & $9 \times 8$ \\
Metastases of renal cancer & $9 \times 6$ \\
Cyst & $8 \times 7$ \\
Myelolipoma & $8 \times 7$ \\
Pheochromocytoma & $8 \times 6$ \\
Adenoma & $8 \times 5.5$ \\
Pheochromocytoma & $8 \times 5$ \\
Metastasis from renal cancer & $8 \times 6$ \\
Adenoma & $8 \times 5$ \\
\hline \hline
\end{tabular}


occasionally identified prior to adrenal vein clipping. The upper adrenal vessels are either cauterized or clipped. Ultrasonic scissors were often used after the division of the main adrenal vein.

The specimen was placed in a bag and extracted through an extension of the incision done for the Hasson technique. The length of the extension depends on the tumor size, and the tumor must be removed from the abdomen carefully to be kept intact for histology examination.

\section{RESULTS}

In 166 patients, 135 laparoscopic procedures were completed successfully, whereas in 14 patients the laparoscopic procedure was converted to open, and 17 patients were treated with the open approach from the start. No conversions were necessary in the group of patients with tumors $>8 \mathrm{~cm}$.

Operative time for laparoscopic adrenalectomies ranged from 65 minutes to 240 minutes. In the large adrenal tumor group, operative time for laparoscopic resection ranged from 150 minutes to 240 minutes. The postoperative hospital stay for laparoscopic adrenalectomy ranged from 1 day to 2 days (mean, 1.5) and from 5 days to 20 days for patients undergoing the open or converted procedure. The mean postoperative stay was 2 days for the group with large tumors resected by laparoscopy. There was minimal blood loss in all patients with laparoscopic resection for tumors $>8 \mathrm{~cm}$ and no need for transfusion.

Mortality and major morbidity did not differ in patients with large tumors when compared with patients with smaller tumors.

Early in our experience, in a patient with morbid obesity, Cushing's syndrome and bilateral macronodular adrenal hyperplasia (adrenal size $2.5 \mathrm{~cm}$ to $4.5 \mathrm{~cm}$ ), the right laparoscopic adrenalectomy was uneventful, whereas the left laparoscopic adrenalectomy, converted to open, was complicated by a low output pancreatic fistula, treated conservatively with success.

One patient with pheochromocytoma developed pulmonary embolism 3 hours after the procedure and succumbed in the intensive care unit (ICU) one month later. The patient initially underwent a laparoscopic approach for an 8-cm tumor, which was converted to open due to difficulty in mobilization and minor but troublesome bleeding obscuring the operative field.

A 70-year-old patient with Conn's syndrome and a $2.5-\mathrm{cm}$ adenoma who had a previous medical history of coronary heart disease, anticoagulant treatment not discontinued in a timely manner, and chronic renal failure died from respiratory failure after 2.5 months of hospitalization in the ICU. The patient was reoperated on 24 hours postoperatively with diffuse retroperitoneal hemorrhaging that was treated successfully.

One patient had a $10 \mathrm{~cm} \times 6.5 \mathrm{~cm}$ adenoma, laparoscopically resected, suspicious for malignancy on imaging and potentially malignant on histological investigation, that recurred after 5 years and hence the patient underwent open resection including the upper pole of the kidney.

At a mean follow-up interval of 96 months after laparoscopic adrenalectomy (range, 8 to 150), resolution of hormonal activity and no evidence of benign tumor recurrence were documented irrespective of tumor size.

\section{DISCUSSION}

Laparoscopic adrenalectomy has become the gold standard in management of most adrenal masses.5,6 In fact, over the last 2 decades, retrospective comparison studies have illustrated the superiority of the laparoscopic approach over the conventional open procedure for the removal of benign functioning and nonfunctioning tumors of the adrenal gland. Laparoscopic procedures are associated with decreased hospitalization time; less operative blood loss; less postoperative discomfort, pain and need for analgesics; faster postoperative recovery; earlier return to everyday activities and diet; and lower overall costs. ${ }^{7-10}$ Based on these considerations, the indications for this technique have been vastly expanded, ${ }^{11}$ and laparoscopic adrenalectomy may even be performed, in select cases, on an outpatient basis. ${ }^{12}$

In the early stages, laparoscopic adrenalectomy was advocated only for the removal of small benign adrenal lesions. Despite the success of this procedure in patients with small adrenal tumors, there has been reluctance for several years to use this approach in patients with larger lesions. However, advantages in technology and experience gained in large institutions have extended the indications of laparoscopic adrenalectomy to include resection of larger adrenal tumors. ${ }^{13}$ Several authors support the laparoscopic approach in lesions $<6 \mathrm{~cm}$, whereas others have performed laparoscopic adrenalectomy of tumors up to $15 \mathrm{~cm}$ without discouraging morbidity rates. ${ }^{14-16}$ Indeed, several studies show that laparoscopic resection of large lesions can be safely performed regardless of the tumor size. ${ }^{17-20}$ Extensive experience in advanced laparoscopic techniques as well 
as in open adrenal surgery are mandatory to manipulate and laparoscopically excise large tumors.

Despite the great experience gained in laparoscopic adrenalectomy, controversy remains in the management of adrenal tumors with high suspicion or evidence of malignancy. ${ }^{21}$

There are still concerns regarding the ability of the laparoscopic approach to totally remove primary malignant lesions that are supported by some cases of local recurrence and peritoneal tumor dissemination following laparoscopic approaches for primary malignancies. ${ }^{22-25}$ Recurrence may be due to incomplete resection or capsular disruption of the tumor during manipulation of the adrenal mass. However, several studies have clearly demonstrated that long-time survival rates with minimally invasive techniques are similar to these in the open approach, whereas there is a significant improvement in quality of life in the postoperative period. ${ }^{26-28}$

The adrenal gland is also a site of metastatic spread for many tumors, mainly because of the rich sinusoidal blood supply. Large metastatic lesions are usually confined within the adrenal gland on presentation, thus representing an ideal target for laparoscopic excision. ${ }^{29-35}$ Laparoscopic surgery for metastatic adrenal tumors up to $10 \mathrm{~cm}$ is definitely a feasible, indicated technique. ${ }^{35,36}$

The interpretation of radiologic characteristics is a cornerstone of preoperative assessment of large masses, because open surgery remains the preferred procedure when malignancy is suspected. Tumor size is a good index but cannot be used as an absolute predictor of malignancy. ${ }^{37}$ It has been estimated that the risk for cancer in adrenal tumors $>6 \mathrm{~cm}$ is 1 in every 60 adrenalectomies performed, ie, $1.67 \% .{ }^{38}$ On the other hand, $13.5 \%$ of adrenocortical carcinomas were diagnosed in patients with adrenal tumors $<5 \mathrm{~cm}$. ${ }^{39}$ Moreover, computed tomography may be associated with approximately a $40 \%$ underestimation of adrenal tumor size compared with the actual size determined in the histological examination. ${ }^{40}$ Despite the improvement in imaging techniques, they lack enough accuracy to exclude primary malignancy. An initial laparoscopic approach can be used to establish a diagnosis, and conversion to the open technique is mandatory if curative resection cannot be performed. The sole widely accepted absolute contraindication for minimally invasive techniques in adrenal lesions is the presence of large primary carcinomas with or without local invasion of nearby structures and/or metastasis to periaortic lymph nodes. ${ }^{41}$ Large but well-encapsulated metastatic adrenal masses without evidence of local inva- sion can be removed laparoscopically, whereas giant benign tumors or tumors $>12 \mathrm{~cm}$ to $14 \mathrm{~cm}$ are not an indication for the laparoscopic technique. ${ }^{42}$

\section{CONCLUSION}

Laparoscopic adrenalectomy can be considered the treatment of choice for all benign adrenal tumors up to $12 \mathrm{~cm}$ to $14 \mathrm{~cm}$ in size. Morbidity, mortality, and hospital stay is similar, irrespective of tumor size, but experience in both laparoscopic and adrenal surgery is necessary.

Large tumors suspected of being a primary malignancy based on imaging characteristics should be approached with the open technique from the start.

\section{References:}

1. Gagner M, Lacroix A, Bolte E. Laparoscopic adrenalectomy in Cushing's syndrome and pheochromocytoma. N Engl J Med. 1992;327(14):1033.

2. Naya Y, Suzuki H, Komiya A, et al. Laparoscopic adrenalectomy in patients with large adrenal tumors. Int J Urol. 2005;12(2):134-139.

3. Parnaby CN, Chong PS, Chisholm L, Farrow J, Connell JM, O'Dwyer PJ. The role of laparoscopic adrenalectomy for adrenal tumours of $6 \mathrm{~cm}$ or greater. Surg Endosc. 2008;22(3):617-621.

4. Liao CH, Chueh SC, Lai MK, Hsiao PJ, Chen J. Laparoscopic adrenalectomy for potentially malignant adrenal tumors greater than 5 centimeters. J Clin Endocrinol Metab. 2006;91(8):3080-3083.

5. Stanley DG. Laparoscopic adrenalectomy. Int Surg. 1994; 79(3):253-258.

6. Gumbs AA, Gagner M. Laparoscopic adrenalectomy. Best Pract Res Clin Endocrinol Metab. 2006;20(3):483-499.

7. Mellon MJ, Sundaram CP. Laparoscopic adrenalectomy for pheochromocytoma versus other surgical indications. JSLS. 2008; 12(4):380-384.

8. Imai T, Kikumori T, Ohiwa M, Mase T, Funahashi H. A case-controlled study of laparoscopic compared with open lateral adrenalectomy. Am J Surg. 1999;178(1):50-53.

9. Smith CD, Weber CJ, Amerson JR. Laparoscopic adrenalectomy: new gold standard. World J Surg. 1999;23(4):389-396.

10. Dudley NE, Harrison BJ. Comparison of open posterior versus transperitoneal laparoscopic adrenalectomy. Br J Surg. 1999; 86(5):656-660.

11. Gill IS. The case for laparoscopic adrenalectomy. J Urol. 2001;166(2):429-436.

12. Mohammad WM, Frost I, Moonje V. Outpatient laparoscopic adrenalectomy: a Canadian experience. Surg Laparosc Endosc Percutan Tech. 2009;19(4):336-337. 
13. Dimas S, Roukounakis N, Kafetzis I et al. Feasibility of laparoscopic adrenalectomy for large pheochromocytomas. JSLS. 2007;11(1):30-33.

14. Telem DA, Nguyen SQ, Chin EH, Weber K, Divino M. Laparoscopic resection of giant adrenal cavernous hemangioma. JSLS. 2009;13(2):260-262.

15. Henry JF, Sebag F, Iacobone M, Mirallie E. Results of laparoscopic adrenalectomy for large and potentially malignant tumors. World J Surg. 2002;26(8):1043-1047.

16. Zografos GN, Kothonidis K, Ageli C, et al. Laparoscopic resection of large adrenal ganglioneuroma. JSLS. 2007;11(4):487-492.

17. Boylu U, Oommen M, Lee BR, Thomas R. Laparoscopic adrenalectomy for large adrenal masses: pushing the envelope. J Endourol. 2009;23(6):971-975.

18. Shen WT, Sturgeon C, Clark OH, Duh QY, Kebebew E. Should pheochromocytoma size influence surgical approach? A comparison of 90 malignant and 60 benign pheochromocytomas. Surgery. 2004;136(6):1129-1137.

19. Tsuru N, Suzuki K, Ushiyama T, Ozono S. Laparoscopic adrenalectomy for large adrenal tumors. J Endourol. 2005;19(5): 537-540.

20. Indupur RR, Nerli RB, Reddy MN, Siddappa SN, Thakkar R. Laparoscopic adrenalectomy for large pheochromocytoma. BJU International. 2007;100:1126-1129.

21. Sturgeon C, Kebebew E. Laparoscopic adrenalectomy for malignancy. Surg Clin North Am. 2004;84(3):755-774.

22. Vassilopoulou-Sellin R, Schultz PN. Adrenocortical carcinoma. Clinical outcome at the end of the 20th century. Cancer. 2001;92(5):1113-1121.

23. Chen B, Zhou M, Cappelli MC, Wolf JS, Jr. Port site, retroperitoneal and intra-abdominal recurrence after laparoscopic acrenalectomy for apparently isolated metastasis. J Urol. 2002; 168(6):2528-2529.

24. Foxius A, Ramboux A, Lefebvre Y, Broze B, Hamels J, Squifflet J. Hazards of laparoscopic adrenalectomy for Conn's adenoma. When enthusiasm turns to tragedy. Surg Endosc. 1999; 13(7):715-717.

25. Hamoir E, Meurisse M, Defechereux T. Is laparoscopic resection of a malignant corticoadrenaloma feasible? Case report of early, diffuse and massive peritoneal recurrence after attempted laparoscopic resection. Ann Chir. 1998;52(4):364-368.

26. Henry JF, Defechereux T, Gramatica L, Raffaelli M. Should laparoscopic approach be proposed for large and/or potentially malignant adrenal tumors? Langenbecks Arch Surg. 1999;384(4): 366-369.

27. Gerber E, Dinlenc C, Wagner JR. Laparoscopic adrenalectomy for isolated adrenal metastasis. JSLS. 2004;8(4):314-319.
28. Valeri A, Borrelli A, Presenti L, et al. Adrenal masses in neoplastic patients: the role of laparoscopic procedure. Surg Endosc. 2001;15(1):90-93.

29. Zografos GN, Markou A, Aggeli $\mathrm{CH}$, et al. Laparoscopic surgery for adrenal tumors. A retrospective analysis. Hormones. 2006;5(1):52-56.

30. Kebebew E, Siperstein AE, Clark OH, Duh QY. Results of laparoscopic adrenalectomy for suspected and unsuspected malignant adrenal neoplasms. Arch Surg. 2002;137(8):948-951.

31. Heniford BT, Arca MJ, Walsh RM, Gill IS. Laparoscopic adrenalectomy for cancer. Semin Surg Oncol. 1999;16(4):293-306.

32. Zografos GN, Farfaras A, Ageli C, Kontogeorgos G, Vasiliadis G, Papastratis G. Laparoscopic adrenalectomy for large adrenal metastasis from contralateral renal cell carcinoma. JSLS. 2007; 11(2):261-265.

33. Marangos IP, Kazazyan AM, Rosseland AR, et al. Should we use laparoscopic adrenalectomy for metastases? Scandinavian multicenter study. J Laparoendosc Adv Surg Tech A. 2009;19(2):181-189.

34. Bendinelli C, Lucchi M, Buccianti P, Iacconi P, Angeletti CA, Miccoli P. Adrenal masses in non-small cell lung carcinoma patients: is there any role for laparoscopic procedures? J Laparoendosc Adv Surg Tech A. 1998;8(3):119-124.

35. Zografos GN, Vasiliadis G, Farfaras AN, Aggeli C, Digalakis M. Laparoscopic surgery for malignant adrenal tumors. JSLS. 2009;13(2):196-202.

36. Sarela AI, Murphy I, Coit DG, Conlon KC. Metastasis to the adrenal gland: the emerging role of laparoscopic surgery. Ann Surg Oncol. 2003;10(10):1191-1196.

37. Novitsky YW, Czerniach DR, Kercher KW, Perugini RA, Kelly JJ, Litwin DE. Feasibility of laparoscopic adrenalectomy for large adrenal masses. Surg Laparosc Endosc Percutan Tech. 2003; 13(2):106-110.

38. Copeland PM. The incidentally discovered adrenal mass. Ann Surg. 1984;199(1):116-122.

39. Barnett CC, Jr., Varma DG, El-Naggar AK, et al. Limitations of size as a criterion in the evaluation of adrenal tumors. Surgery. 2000;128(6):973-982.

40. Lau H, Lo CY, Lam KY. Surgical implications of underestimation of adrenal tumour size by computed tomography. $\mathrm{Br} J$ Surg. 1999;86(3):385-387.

41. Gagner M, Pomp A, Heniford BT, Pharand D, Lacroix A. Laparoscopic adrenalectomy: lessons learned from 100 consecutive procedures. Ann Surg. 1997;226(3):238-246.

42. Zografos GN, Korkolis D, Georgoutsos P, et al. Giant myelolipoma of the right adrenal gland. Int J Clin Pract. 2002;56(4): 319-120. 